\title{
A model for simulating the timelines of field operations at a European scale for use in complex dynamic models
}

\author{
N. J. Hutchings ${ }^{1}$, G. J. Reinds ${ }^{2}$, A. Leip ${ }^{3}$, M. Wattenbach ${ }^{4, *}$, J. F. Bienkowski ${ }^{5}$, T. Dalgaard ${ }^{1}$, U. Dragosits ${ }^{6}$, \\ J. L. Drouet ${ }^{7}$, P. Durand ${ }^{8}$, O. Maury ${ }^{7}$, and W. deVries ${ }^{9}$ \\ ${ }^{1}$ Aarhus University, Department of Agroecology, Blichers Allé 20, 8830 Tjele, Denmark \\ ${ }^{2}$ Alterra, Wageningen University and Research Centre, P.O. Box 47, 6700 AA Wageningen, The Netherlands \\ ${ }^{3}$ European Commission - DG Joint Research Centre, Institute for Environment and Sustainability, Via E. Fermi 2749, \\ 21027 Ispra (VA), Italy \\ ${ }^{4}$ Institute of Biological and Environmental Sciences, School of Biological Sciences, University of Aberdeen, \\ 23 St. Machar Drive, Aberdeen, AB24 3UU, Scotland, UK \\ ${ }^{5}$ IAFE PAS, Poznan, Poland \\ ${ }^{6}$ CEH Edinburgh, Bush Estate, Penicuik, Midlothian EH26 0QB, Scotland, UK \\ ${ }^{7}$ INRA-AgroParisTech, UMR EGC, Thiverval-Grignon, France \\ ${ }^{8}$ INRA, UMR 1069 Soil AgroHydrosystems spatialisation, 35000 Rennes, France \\ ${ }^{9}$ Environmental Systems Analysis Group, Wageningen University, P.O. Box 47, 6700 AA Wageningen, The Netherlands \\ *now at: Helmholtz Centre Potsdam, GFZ German Research Centre For Geosciences, Section 5.4 Hydrology, Telegrafenberg, \\ 14473 Potsdam, Germany
}

Correspondence to: N. J. Hutchings (nick.hutchings@ agrsci.dk)

Received: 29 June 2012 - Published in Biogeosciences Discuss.: 9 August 2012

Revised: 13 October 2012 - Accepted: 25 October 2012 - Published: 14 November 2012

\begin{abstract}
Complex dynamic models of carbon and nitrogen are often used to investigate the consequences of climate change on agricultural production and greenhouse gas emissions from agriculture. These models require high temporal resolution input data regarding the timing of field operations. This paper describes the Timelines model, which predicts the timelines of key field operations across Europe. The evaluation of the model suggests that while for some crops a reasonable agreement was obtained in the prediction of the times of field operations, there were some very large differences which need to be corrected. Systematic variations in the date of harvesting and in the timing of the first application of $\mathrm{N}$ fertiliser to winter crops need to be corrected and the prediction of soil workability and trafficability might enable the prediction of ploughing and applications of solid manure in preparation for spring crops. The data concerning the thermal time thresholds for sowing and harvesting underlying the model should be updated and extended to a wider range of crops.
\end{abstract}

\section{Introduction}

Complex dynamic models of carbon and nitrogen provide an insight into the interactions between agricultural management and the biotic/abiotic processes within agroecosystems. This is particularly true when investigating the possible consequences of climate change on greenhouse gas emissions from agriculture, since climate impacts occur at the process scale. However, obtaining appropriate values for parameters and driving variables presents investigators with a challenge; such models typically contain a large number of parameters and operate with a temporal resolution of one day, so require input data with a high temporal resolution. Furthermore, it is relevant to conducting such investigations at a high spatial resolution because the predicted changes in response to climate change vary regionally as a function of land use and soil properties (De Vries et al., 2012). Whilst it can be reasonably argued that some parameters are not inherently locationdependent (e.g. the light use efficiency of a particular crop), this is not true for the driving variables. On a given field,

Published by Copernicus Publications on behalf of the European Geosciences Union. 
meteorological variables (e.g. temperature, rainfall) and field operations (ploughing, sowing, fertilization, harvesting) are the main driving variables. There are good agronomic reasons why farmers take the weather into account when making decisions concerning field operations. For example, applying $\mathrm{N}$ fertiliser too much in advance of sowing could result in a low fertilisation efficiency, if rainfall leads to the $\mathrm{N}$ being leached below the rooting zone or creates conditions that encourage denitrification. As a consequence, the timing is likely to vary in response to both year-to-year differences in weather and long-term changes in climate.

The mechanisms driving both the direct emissions of greenhouse gases (GHG), such as $\mathrm{N}_{2} \mathrm{O}$ and their indirect emissions (e.g. by $\mathrm{NH}_{3}$ emission and deposition and by $\mathrm{NO}_{3}$ leaching), are sensitive to short-term weather conditions (Van Groeningen et al, 2005). Complex agroecosystem models attempt to describe these mechanisms, so researchers wishing to use them at the European scale must estimate agricultural management in the past and future. There has been significant progress regarding the collation of high-spatial resolution meteorological data for the past and the prediction of future climate (New et al., 2002; Klok and Klein Tank, 2009). In contrast, there has been less progress towards obtaining realistic field operation data at the European scale. Since such data cannot be obtained using automated techniques (e.g. from remote sensing), this requires the use of expensive standardised survey methods. Consequently, these data are often not available for the past or present in Europe, so a purely statistical modelling approach to predicting the timing of past and future field operations is not possible.

The need for some location-specific driving variables has been recognized for many years. The Crop Growth Modelling System (CGMS, http://www.marsop.info/marsopdoc/ cgms92/) of the EU Joint Research Centre was begun in the early 1990s (see van Diepen and Boogaard, 2009) and remains operational today. The CGMS generates locationspecific average sowing and harvesting dates for these crops for a large part of Europe by relating these events to thermal time and an interpolation procedure. Additional conditions, related to the likely soil moisture content, were also imposed.

Part of the NitroEurope EU integrated research project (www.nitroeurope.eu) focussed on the simulation of $\mathrm{N}_{2} \mathrm{O}$ emissions and carbon sequestration from European agriculture, for the period 1971-2030. This included the use of complex dynamic $\mathrm{C}$ and $\mathrm{N}$ crop and soil models at a high spatial resolution across Europe; nearly 42000 relatively homogenous spatial units called NCUs (NitroEurope Calculation Units) based on an overlay of administrative units at NUTS2 (Statistical Office of the European Communities, 2003), soil mapping units according to the classes within the Soil Geographic Database of the European Commission (http://eusoils.jrc.ec.europa.eu/esdb_ archive/ESDBv2/fr_intro.htm), and slope classes (i.e. 0-2\%, $2-8 \%, 8-15 \%, 15-25 \%,>25 \%$ ), calculated on the basis of the Catchment Characterisation and Modelling Digital Ele-

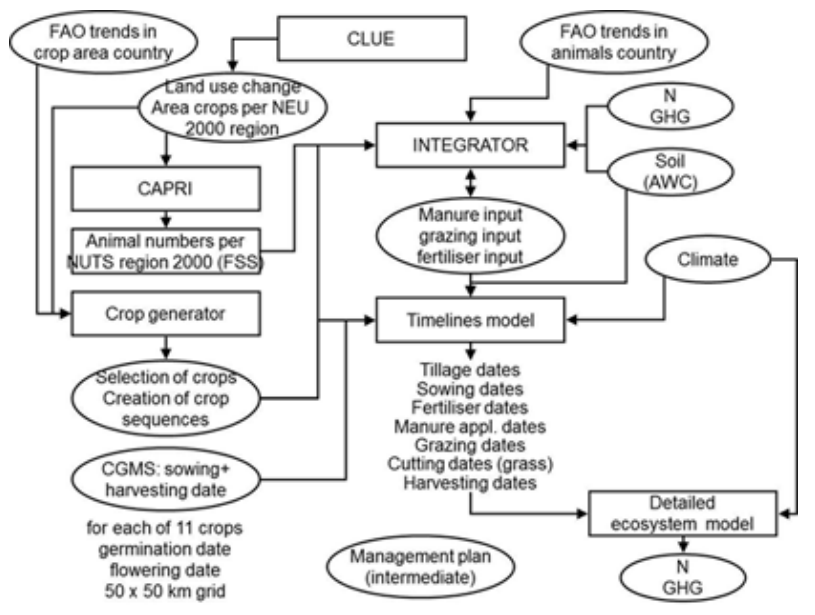

Fig. 1. Location of the Timelines model within the overall modelling structure.

vation Model, (CCM 250 DEM, 2004). In addition a criterion on altitude was imposed limiting the difference in the average altitude of polygons in each NCU to $200 \mathrm{~m}$. The models used were DNDC-EUROPE (Leip et al., 2008), Mobile DNDC (De Bruijn et al., 2009) and DailyDayCent (Del Grosso et al., 2006). Given that over this $60 \mathrm{yr}$ period there have been marked changes in climate already and further changes are predicted, the use of time-averaged field operation data were not considered appropriate for model input. While these models have the ability to predict the timing of one or more field operations, one of the objectives of the exercise undertaken in the NitroEurope project was to compare the results of the different complex dynamic models. To avoid biasing the results towards a particular model, the driving variables needed to be generated independently.

Three models were used in the preparation of input data to these dynamic models (Fig. 1). The crop generator created six crop sequences for each relevant NCU in each year, based on historical or projected crop shares (Wattenbach et al., 2013) and changes in land use based on the CLUE model (De Vries et al., 2012). The second model (INTEGRATOR) simulated the amount of mineral $\mathrm{N}$ fertiliser and a range of animal manures applied to each crop and the annual deposition of $\mathrm{N}$ from the atmosphere, for each location in each year (De Vries et al., 2011). The third model simulated the timing (timelines) of field operations on each crop at each location in each year, and the use of field-scale measures to mitigate greenhouse gas emissions.

In this paper, we describe this latter model and compare the results with data that was collected as part of the same project. 


\section{Methods}

The methodology for the Timelines model was developed by a process of trial and error. In addition to a description of the final methodology, we include in this section a description of developments that proved not to be suitable for the operational model. This is not only to provide an explanation of the methodology finally adopted, but also to alert anyone contemplating modifications or improvements to the methodology of the pitfalls that might lie in their way.

\subsection{Specifications of the timelines model}

The data to be generated were the timing of tillage, sowing, fertilisation with mineral fertiliser and manure and harvesting. Timelines of field operations needed to be generated for all crops and all NCUs to be simulated. The former was defined here to be all arable crops included in the CAPRI model (Britz and Witzke, 2008; see Table 1). Furthermore, although CAPRI does not distinguish between spring and winter cropping, the crop generator adds this information. The model requires data at an adequate spatial resolution at the European scale, for timelines to be generated at the daily scale, and to be consistent for multiple years. This latter constraint was imposed to support initialisation of the organic matter pools of the soil modules in the ecosystem models ("spinning up") and simulation runs of sufficient duration such that changes in soil C sequestration could be modelled.

The major assumption behind the Timelines model is that the sowing and harvesting dates of crops can be related to accumulated air temperature, and that these two events can be used to frame all other field operations. It is also assumed that agronomic logic can be used to place the timing of ploughing, $\mathrm{N}$ fertilisation and manuring operations relative to these dates. More specifically, this logic assumes that farmers time fertilisation and manuring operations to maximise nitrogen use efficiency for crop production. In both cases, it was accepted beforehand that these were gross simplifications. However, they permitted the generation of timelines with the minimum of empirical input data, namely air temperature.

\subsection{Sowing and harvesting}

Although data concerning the timing of field operations are collected to varying extents in countries across Europe, to our knowledge, the data used CGMS, which represents the only Europe-wide harmonised dataset available. This dataset was constructed using observations of the sowing, ripening and harvesting dates made in the mid-1990s for a range of crops at locations across Europe. The values were subsequently interpolated onto the $50 \times 50 \mathrm{~km}$ MARS meteorological grid to give complete coverage of the areas where these crops were grown. However, the CGMS uses a single dataset for all years, an approach that we considered inadequate for use
Table 1. CAPRI crops and their Timelines equivalents.

\begin{tabular}{|c|c|c|c|}
\hline $\begin{array}{l}\text { CAPRI } \\
\text { CODE }\end{array}$ & $\begin{array}{l}\text { CAPRI } \\
\text { description }\end{array}$ & $\begin{array}{l}\text { Sowing } \\
\text { season }\end{array}$ & $\begin{array}{l}\text { Timelines } \\
\text { model crop }\end{array}$ \\
\hline SWHE & Common wheat & $\begin{array}{l}\text { Spring } \\
\text { Winter }\end{array}$ & $\begin{array}{l}\text { Spring wheat } \\
\text { Winter wheat }\end{array}$ \\
\hline DWHE & Durum wheat & Spring & Spring wheat \\
\hline BARL & Barley & $\begin{array}{l}\text { Spring } \\
\text { Winter }\end{array}$ & $\begin{array}{l}\text { Spring barley } \\
\text { Winter barley }\end{array}$ \\
\hline RYEM & Rye & & Spring barley \\
\hline OATS & Oats & & Spring barley \\
\hline MAIZ & Maize & & Grain maize \\
\hline OCER & Other cereals & & Spring barley \\
\hline POTA & Potatoes & & Potatoes \\
\hline SUGB & Sugar beet & & Sugar beet \\
\hline PARI & Rice & & Spring barley \\
\hline ROOF & Other root crops & & Sugar beet \\
\hline SUNF & Sunflower & & Sunflower \\
\hline RAPE & Rape and turnip rape & & Winter rape \\
\hline SOYA & Soya & & Spring barley \\
\hline TEXT & $\begin{array}{l}\text { Fibre and oleaginous } \\
\text { crops; cotton }\end{array}$ & & Spring barley \\
\hline TOBA & Tobacco & & Spring wheat \\
\hline OIND & $\begin{array}{l}\text { Other non-permanent } \\
\text { industrial crops }\end{array}$ & & Winter wheat \\
\hline PULS & Dry pulses & & Spring wheat \\
\hline FALL & Fallow land & & Fallow \\
\hline MAIF & Fodder maize & & Fodder maize \\
\hline OCRO & $\begin{array}{l}\text { Other crops; permanent } \\
\text { industrial crops }\end{array}$ & & Winter wheat \\
\hline
\end{tabular}

in our study, since there have been important trends in the climate over the period we wished to consider. Furthermore, the range of crops considered was more limited than the range we wished to include in our modelling.

To make the sowing and harvesting dates responsive to differences in the seasonal climate between years, we used a thermal time approach. The thermal time is the sum of the product of the time in days and the difference between the air temperature and a base temperature, below which temperature is ignored; i.e. if $\tau_{t}$ is the thermal time (degree days) at time $t$ (days), and $\theta_{\mathrm{b}}$ is the base temperature (celsius), then:

$\tau_{t}=\sum_{k=t_{0}}^{t} \max \left(\left(\theta_{k}-\theta_{\mathrm{b}}\right), 0\right)$

where $\theta_{k}$ is the air temperature (celsius) on day $k$. For simplicity, a value of zero was used for the base temperature throughout this work.

We first back-calculated the reference thermal time for the data in the CGMS dataset, using the average air temperature data for the years 1985 to 1995 . The mean daily air temperature was estimated by averaging the minimum and maximum daily air temperatures in the MARS dataset. This reference thermal time data were then used to calculate sowing and harvesting data across Europe for the historical climate record for 1971 to 2000 and to the predicted climate 
for the period 2000 to 2030 (using the A1 climate scenario) to generate the predicted crop-specific dates of sowing and harvesting across Europe. The meteorological data for the period 1970-2000 were obtained by combining the MARS grid weather (Orlandi and Van der Goot, 2003) with interpolated monthly climate data at $10^{\prime} \times 10^{\prime}$ spatial resolution (Mitchell et al., 2004). For the period 2001-2030, recent simulations from the REMO model (Jacob, 2001) were provided by the Max-Planck-Institute for Meteorology, Germany. Meteorological data were processed as described in Cameron et al. (2012) and de Vries et al. (2012). The CGMS dataset includes the following crops: winter wheat, winter barley, winter rape, spring barley, spring rape, spring wheat, sugar beet, potatoes, sunflower, grain maize and fodder maize. To enable the crops not included in the CGMS dataset to be modelled, replacement crops were identified (Table 1).

Initial simulations with the model as described above identified a number of issues. The first was that, in a small number of instances, either the sowing or the harvesting dates were not available for a crop in the MARS grid where the crop generator predicted that the crop would be cultivated. In this situation, the search was progressively expanded stepwise in all compass directions until the crop was found in one or more MARS grids. If a single expansion encountered the crop in more than one grid, the average date was used.

A second problem was that, on some occasions when the crop generator predicted the planting of a winter crop, the sowing date for these crops was before the harvesting date for the preceding crop. This was probably due to a combination of the relatively short period between harvesting and sowing, and uncertainty introduced into the determination of the dates by the original CGMS interpolation procedure and the further data processing described above. However, for forage maize, which is commonly harvested later than other arable crops and is rarely followed by winter cereals, this appeared to be due to a failure to constrain the crop generator accordingly. The solution adopted in the problematic instances was to advance the crop harvesting to a date five days prior to the sowing date of the winter crop. This was to allow the winter crop sufficient time to become established and thereby avoid unrealistically low crop coverage during the winter period.

A third problem encountered was that, with climate warming, the sowing dates of winter cereals advanced towards mid-summer. This resulted in the autumn-sown cereals being predicted to enter the winter at an unrealistically advanced development stage. The solution adopted here was to abandon the use of the thermal time concept to determine the sowing date of winter cereals and to rely on the original, static dataset.

\subsection{Other field operations}

In general, the timing of other field operations is assumed to be closely related to the sowing date. However, for applica- tions of mineral fertiliser and animal slurry to winter cereals, the timing is related to the start of the growing season.

Ploughing in preparation for all crops was assumed to occur three and two days prior to the sowing date, respectively.

The timing of manure applications was assumed to vary according to the manure type. The $\mathrm{N}$ in solid manure is mainly in the organic form, so must be mineralised before it can become available to the crop. The rate of mineralisation is improved if the manure is incorporated in the soil, and the utilisation of this mineralised $\mathrm{N}$ is improved if a crop is established shortly thereafter. As a consequence, such practices are either mandatory for land within areas identified as being vulnerable to nitrate leaching under the EU Nitrates Directive (EEC, 1991) or advisable for all arable land (Chambers et al., 2001; Webb et al., 2013). Applications of solid manure to both spring and winter crops were therefore placed five days prior to the sowing date (i.e. two days before ploughing).

For spring crops, applications of animal slurry coincided with the application of solid manure, whereas for winter crops the applications were timed to coincide with the start of the growing season. The start of the growing season for the winter crops at a given location was equated to the sowing date for spring barley at the same location.

The timing of fertiliser applications was assumed to be designed to promote efficient use of the fertiliser $\mathrm{N}$; the annual amount is applied in two applications. The first application was assumed to consist of $20 \%$ of the annual amount and to be made 5 days prior to sowing (spring crops) or at the start of the growing season (winter crops). The second application, of the remaining $80 \%$, was assumed to be made after $20 \%$ of the growing season has elapsed. This distribution was intended to match the supply of $\mathrm{N}$ to the absorption potential of the crop, bearing in mind that manure $\mathrm{N}$ will often be supplied prior to sowing.

This timing was subsequently modified to ensure that the second fertiliser application did not take place within 21 days of harvesting.

\subsection{Atmospheric N deposition}

The annual atmospheric $\mathrm{N}$ deposition is calculated on the basis of $\mathrm{NH}_{3}$ and $\mathrm{NO}_{\mathrm{x}}$ emissions from agroecosystems calculated by the INTEGRATOR model (De Vries et al., 2011, 2012), combined with historic EMEP data on $\mathrm{NO}_{\mathrm{x}}$ emissions and an emission-deposition matrix for $\mathrm{NH}_{3}$ and $\mathrm{NO}_{\mathrm{x}}$, derived from the EMEP model (Simpson et al., 2006, 2012). This INTEGRATOR input was output from the Timelines model as a single operation, timed on 1 January each year. The ecosystem models then distributed this $\mathrm{N}$ equally on a daily basis. For 2020 the non-agricultural N emission scenario was used that reflects current legislation, which was developed for the Thematic Strategy on Air Pollution of the EU (Amann et al., 2007). From 2020 onwards, deposition was assumed to be constant. 


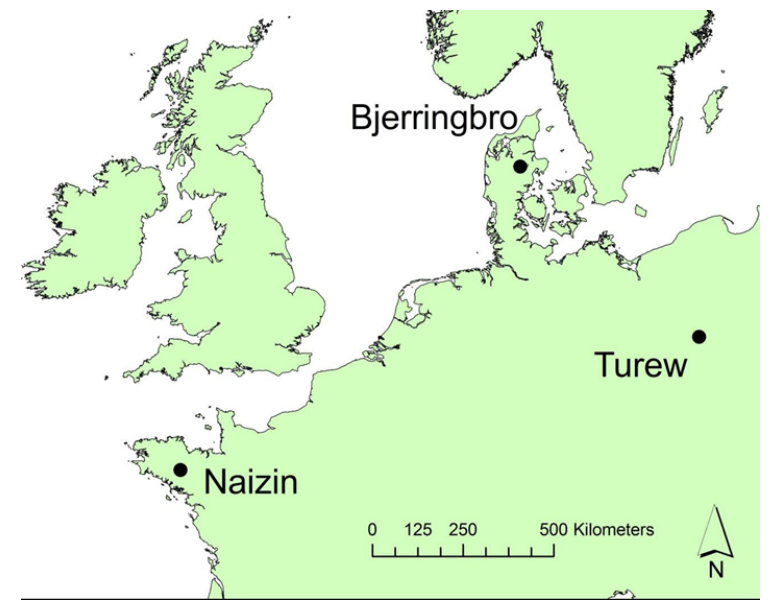

Fig. 2. Location of the Danish (Bjerringbro), French (Naizin) and Polish (Turew) landscape sites.

\subsection{Implementation}

The model was implemented in the $\mathrm{C}++$ programming language, using the Eclipse development environment and the GNU C ++ compiler. The software is freely available at http: //afoludata.jrc.ec.europa.eu (select NitroEurope project), together with instructions for use and details of the input and output file formats. The input from the crop generator and INTEGRATOR models consisted of separate, annual data concerning

- the crop grown;

- the application of $\mathrm{N}$ as ammonium and nitrate;

- the amounts of $\mathrm{N}$ and $\mathrm{C}$ applied in solid manure and slurry originating from cattle, pigs, sheep/goats and poultry (solid manure only);

- the $\mathrm{N}$ deposited from the atmosphere.

The data concerning a particular field operation consisted of the date when the operation was initiated, together with a variable number of operation-specific supplement. For example, the supplement associated with a manure application included the amount and type of animal manure applied, while, for harvesting, the supplement included the method used to harvest a crop. Estimated crop yield was required by a number of the ecosystem models; this was provided by the fertilisation/manure model and the information was attached to the harvesting operations. Full technical details can be found at http://afoludata.jrc.ec.europa.eu/index.php/ dataset/detail/219.
Table 2. Average error in predicted date of field operations for selected crops.

\begin{tabular}{lrrrr}
\hline Crop & \multicolumn{4}{c}{ Average error (predicted - actual) (days) } \\
\hline & Sowing & Ploughing & 1st Fertilisation & Harvesting \\
\cline { 2 - 5 } Spring barley & 3 & 46 & 12 & 21 \\
Maize & 11 & 81 & -4 & 5 \\
Winter barley & 8 & -12 & 42 & 22 \\
Winter wheat & 1 & -14 & 23 & 8 \\
\hline
\end{tabular}

Table 3. Average error in predicted date of field operations for the selected crops, by landscape.

\begin{tabular}{lrrrr}
\hline \multirow{2}{*}{ Country } & \multicolumn{4}{c}{ Average error (predicted - actual) (days) } \\
\hline & Sowing & Ploughing & 1st Fertilisation & Harvesting \\
\cline { 2 - 5 } Denmark & 13 & 13 & 8 & 14 \\
France & -9 & -39 & 27 & 1 \\
Poland & 14 & 102 & 19 & 28 \\
\hline
\end{tabular}

\section{Evaluation}

\subsection{Data source}

The NitroEurope project included a component concerning $\mathrm{N}$ transformations and transport at the landscape scale. As part of this component, case study areas were established in a number of European countries. Of these, the timings of field operations from three landscape areas were extracted for evaluating the Timelines model. The landscapes were in Bjerringbro, Denmark $\left(56.3^{\circ} \mathrm{N}, 9.7^{\circ} \mathrm{E}\right)$, Naizin, France $\left(48.0^{\circ} \mathrm{N}, 2.8^{\circ} \mathrm{W}\right)$, and Turew, Poland $\left(52.0^{\circ} \mathrm{N}, 16.8^{\circ} \mathrm{E}\right)$ (Fig. 2).

The data collected by survey from these study areas included dates of field operations for a single crop year (20072008), which can be compared with the simulated results by the Timelines model. The survey results were stored in a Microsoft Access database for each landscape. All field operation data for each case study area were exported from the Access database in XML format, with individual operations subsequently extracted. Finally, since the data did not appear to be normally distributed, median dates for the operations were calculated. For fertilisation events, which are assumed to occur twice per growing season in the Timelines model, the partitioning of fertilisation events between the first and second application periods was made visually from plotted data. In some instances, it was clear that there was only one application period, in which case the second application date was not calculated.

Two example datasets, one for a winter crop (winter wheat in France) and one for a spring crop (potatoes in Poland), are shown in Fig. 3. 

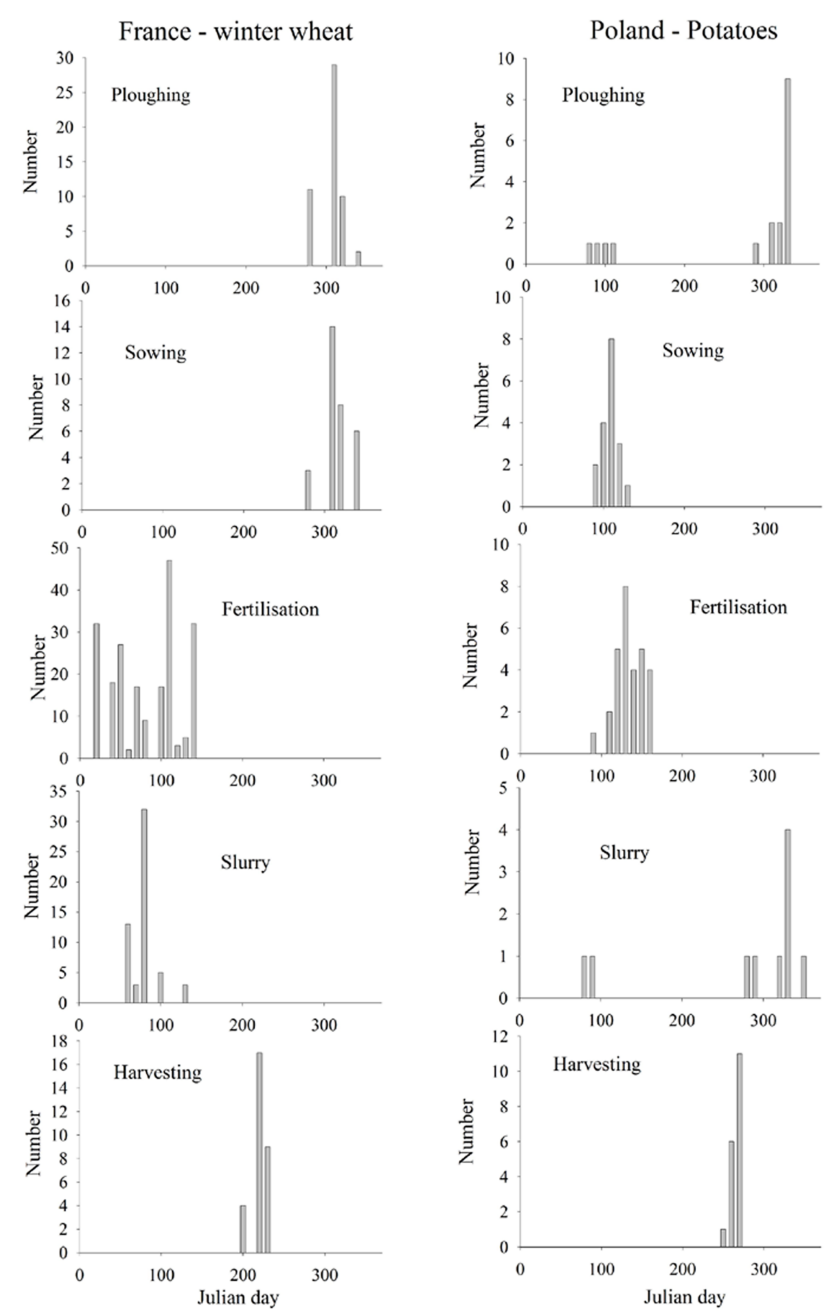

Fig. 3. Examples of field operation timelines for winter wheat in France and potatoes in Poland. Number $=$ number of events recorded.

\subsection{Comparison of recorded and predicted field operations}

The actual and predicted data from the NitroEurope landscape study areas concerning sowing, harvesting, ploughing, fertilisation, application of slurry and application of solid manure are shown in the Figs. 4-8 and in more detail in the Tables S1 to S6, respectively (see Supplement). The number of field operations recorded varied considerably between areas and crops; crops for which there were five or fewer records were omitted. Two spring crops (spring barley and maize) and two winter crops (winter barley and winter wheat) were adequately represented in all three landscapes. For these crops, the mean differences between the median recorded dates and predicted dates were calculated for each crop (Table 2) and landscape (Table 3).

For sowing, there is some evidence to suggest that the absolute magnitude of the difference between the predicted and

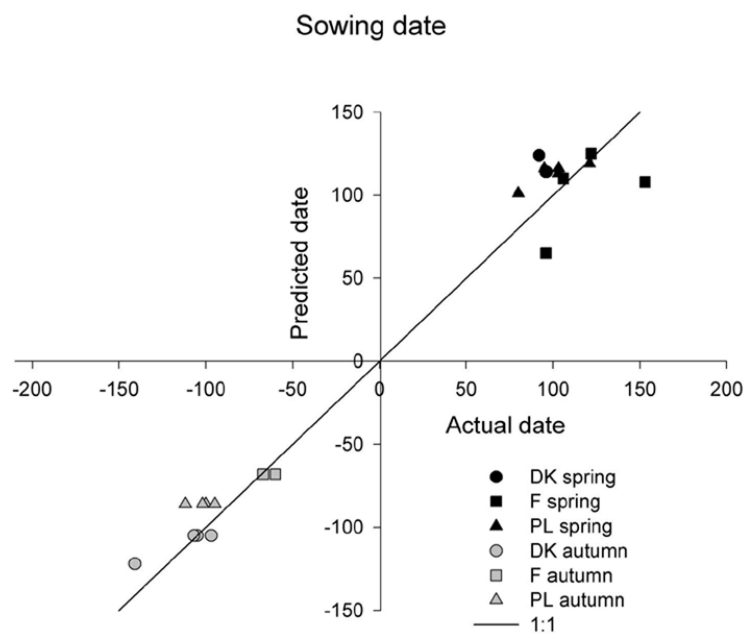

Fig. 4. Comparison of predicted and actual sowing dates. Dates are shown relative to the year of harvesting.

median dates decreased with the number of records, reflecting the effect of the large range of dates recorded in each landscape (Table S1 in the Supplement). There were major differences between the landscapes regarding the performance of the model. In Denmark, the model predicted a sowing date consistently later than recorded. This trend was visible for most winter crops, across all landscapes. For the crops that can be compared between locations (Table 2), there is a consistent tendency for the predicted date to be later than the recorded date. For harvesting, there are large errors for both sugar and fodder beet and possibly also for maize. For the crops that can be compared (Table 2), the predicted harvesting dates for both spring and winter barley are later than those recorded. For ploughing in preparation for the sowing of spring crops, the model assumes that the ploughing also occurs the spring. However, for some spring crops (in Poland, for most crops), the ploughing occurred predominantly in the autumn. This can be seen in Table 3, where data for the field operations for the selected crops are averaged by landscape. For the application of mineral $\mathrm{N}$ fertiliser, there are small errors in the prediction for maize. The predicted application dates for winter crops are consistently too late in the season (Table 2). For a number of crops, the distribution of dates was clearly monotonic and no second application period could be calculated. There were fewer data for the date of slurry and solid manure applications, so these operations are not included in Tables 2 and 3. The notable features are instances of slurry application in the autumn and of solid manure applications in the spring in Denmark, in association with winter crops. 
Harvesting date

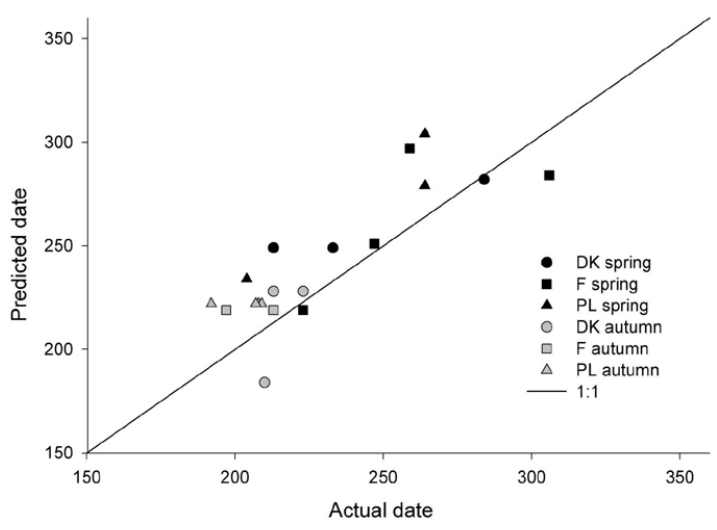

Fig. 5. Comparison of predicted and actual harvesting dates.

\section{Discussion}

\subsection{Performance of the model}

There was a clearer relationship between the predicted and measured sowing dates for autumn-sown crops than for spring-sown crops (Fig. 4). The temperature constraint on the date of sowing will be similar for all spring crops, so it is likely that other factors play an important role in determining the date of sowing, e.g. soil moisture constraints on trafficability and workability or competition for labour and machinery. The only exception is maize, which as a $\mathrm{C} 4$ plant is more temperature sensitive than the remaining, predominantly C3 crops. A later sowing date than for other crops would therefore be expected and this was the case in France and Poland (but not Denmark). In contrast to the spring, the timing of the sowing of winter crops is less likely to be constrained by soil conditions, since the soil is likely to be drier at this time. The autumn sowing period is mainly constrained on one side by the harvesting date of the previous crop and, on the other, the wish to avoid the crop developing so extensively before entering the winter that there is an increased risk of damage by frost, snow or disease. The predicted dates for harvesting were about 10-20 days later than recorded in practice (Fig. 5). This is the reverse of the expected situation; the CGMS data are based on the dates for ripening rather than harvesting, so the need on occasions for other conditions to be satisfied (e.g. to allow cereal crops to dry sufficiently for storage) would be expected to delay harvesting past the time of ripening. This could be due to changes in the crop varieties grown since the 1990s or to interpolation errors in the thermal time in the CGMS or in the meteorological data.

The observations indicate that ploughing in preparation for the sowing of spring crops can occur both in the spring and autumn (Fig. 6). Anecdotal evidence from Poland and France suggests that ploughing in the autumn is common on soils that are likely to be too wet to plough in the spring (either
Ploughing date

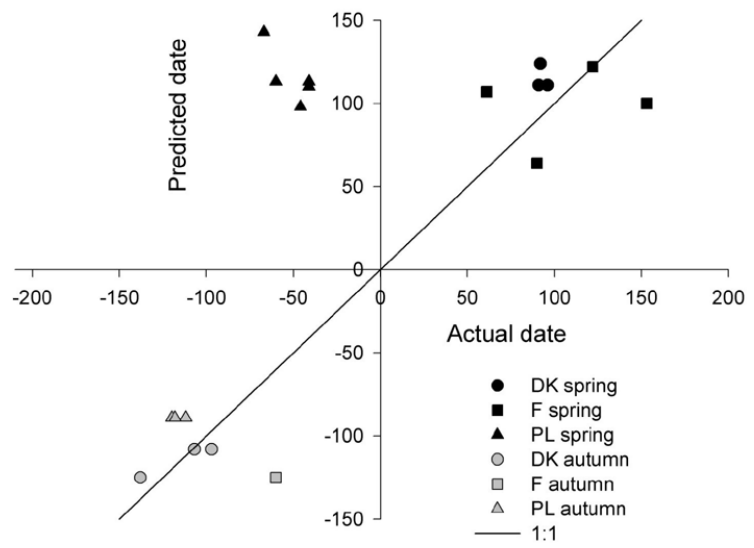

Fig. 6. Comparison of predicted and actual ploughing dates.

due to a high clay content or high water table); the chances that the soils are more workable in the autumn may be higher. The model might therefore be improved by taking into account the effect of soil moisture conditions on workability and trafficability. However, this would require the addition of a soil water model, which is non-trivial and would demand an increased numbers of input variables and parameters. These are important considerations if the model is to be used for large areas.

The assumption that the first application of mineral fertiliser to winter crops in the spring coincides with the start of plant growth (equated in the model to the sowing date of spring barley) appears to be incorrect; according to the landscape surveys, the fertiliser applications are made somewhat earlier than that date (Fig. 7). For those winter crops that can be compared across landscapes, the actual date of first application appears to be about one month before that predicted by the model. The assumption in the model that the annual fertiliser inputs are split between two application dates is sometimes incorrect. For maize, this may be a systematic effect; the growth of maize occurs over a shorter and later period than for the $\mathrm{C} 3$ crops, so farmers may consider that the risk of losing fertiliser $\mathrm{N}$ by leaching or denitrification is sufficiently low that a single application date is adequate. The current model does not take into account any interaction between the mineral fertiliser and organic manure applications; a farmer wishing to manage nutrients efficiently would manage both sources simultaneously. For example, if applying a substantial quantity of organic manure in the spring, the farmer may omit the first spring application of fertiliser $\mathrm{N}$. An additional source of error in the present study is that visually estimating the boundaries of the periods for the first and second applications of fertiliser was sometimes difficult; a more objective, statistical approach would be preferable.

The solid manure applications associated with spring cropping that are sometimes observed to be made in the previous 
Fertilisation dates

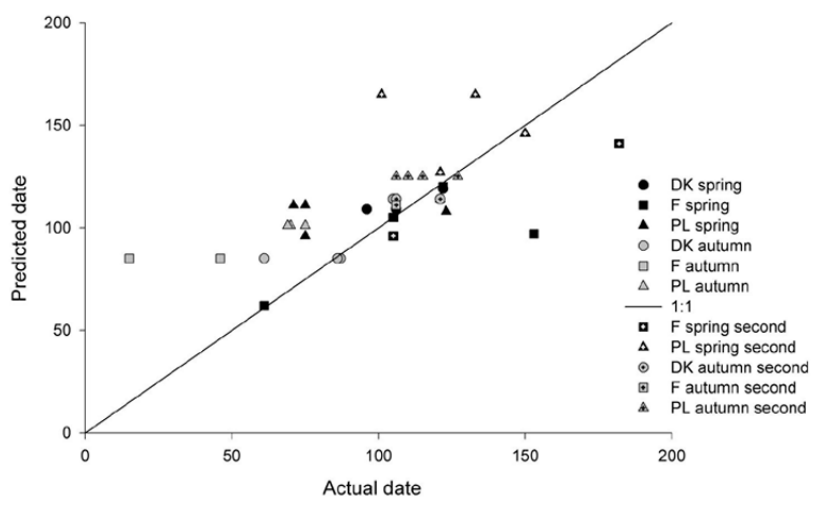

Fig. 7. Comparison of predicted and actual dates for the first and second applications of fertiliser.

autumn (Fig. 8) can probably be explained by the desire to incorporate these manures and hence link the date of application to the timing of ploughing (see above). There is also some evidence that solid manure may be applied in the spring to winter crops.

\subsection{Scope for improvement}

The current assessment of the Timelines model suggests that it broadly fulfils the function for which it was constructed but that there is still room for significant improvement. The variation in the timing of sowing of spring crops and the occurrence of autumn ploughing in preparation for spring sowing shows the importance of considering the effect of the trafficability and workability of clay-rich or poorly-drained soils. The introduction of a soil moisture model would allow such conditions to be predicted. The timing of the first application of $\mathrm{N}$ fertiliser to winter crops needs to be brought forward by about one month, and the timing of the second application to cereal crops could be improved by relating it to predictions of the appropriate cereal growth stage.

Predicting the timing of applications of manure is particularly difficult. Unless obliged or persuaded to value the nutrients contained in manures, farmers are likely to choose to apply them when labour and machinery are least busy and when soil conditions permit trafficking with application equipment, i.e. on frozen soil during the winter, without regard to nutrient recovery. This leads to an extended manure application period. However, the progressive enforcement of the EU Nitrates Directive has led to the introduction of obligatory balanced fertilisation and restrictions on autumn and winter applications of organic manures over an increasingly large area of the EU (CEC, 2007), both of which will tend to concentrate manure applications into the spring period. Since the Timelines model assumes good nutrient management, continued enforcement of the Nitrates Directive, implementation of the EU Water Framework Directive and the
Manure application dates

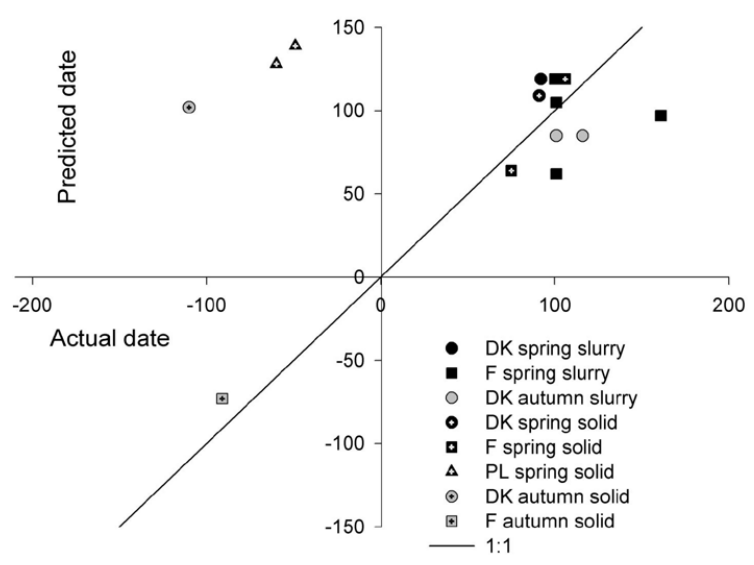

Fig. 8. Comparison of predicted and actual dates for the application of slurry and solid manure.

effect of increasing energy prices on the cost of mineral fertiliser $\mathrm{N}$, it is likely that the predictions regarding manure applications will improve with time. However, further work is necessary if the Timelines model is to be used in connection with the modelling of historical production or nutrient flows.

The model is currently not able to accommodate double cropping. This makes the model less applicable to southern European countries. Furthermore, since climate change may lead to a northward migration of the geographic boundary of the area where double cropping is feasible, this constraint is likely to grow with time.

\subsection{Future}

The advisability of using the Timelines model when using complex ecosystem models in the future depends on the objective of the study being undertaken. In situations where the objective is an inter-comparison between different ecosystem models or the ecosystem model available does not allow for weather-dependent timing of field operations, the model may be useful. However, it will often be preferable for weatherdependent timing of field operations to be introduced into the ecosystem models themselves. This removes the risk of internal inconsistencies in the modelling system, e.g. when the Timelines model predicts that a crop should be harvested while the ecosystem model predicts that it is not yet ripe.

The evaluation undertaken here was limited by the resources available within the NitroEurope project, and there is scope for a more thorough analysis of the data from the $\mathrm{Ni}$ troEurope landscapes, e.g. concerning the relationships between different field operations. Similar data also exist from other EU or national research projects; given the scarcity of such data, there is a need to locate and collate these datasets, and undertake a more detailed analysis than was possible 
here. This might in particular allow the evaluation to be extended into southern Europe.

The current model is heavily reliant on the empirical data on sowing and harvesting dates currently used within CGMS. The range of crops included is limited and the data are now quite old, so do not reflect modern crop varieties. In addition, the data do not reflect the introduction of new crop varieties or the effect of climate change and crop breeding on the movement of the northern boundary for the cultivation of certain crops, such as maize. As ecosystem models become more complex and are increasingly used to inform policymaking, it is important for the quality of the predictions from those models that the quality of the driving variables keeps pace. This argues for further work on predicting the timing of field operations but not least, for improved empirical data.

\section{Conclusions}

The evaluation of the Timelines model suggests that it is capable of simulating the timing of field operations for some but not all arable crops at different locations across Europe. There were systematic variations in the date of harvesting and in the timing of the first application of $\mathrm{N}$ fertiliser to winter crops that need to be corrected. The addition of a soil moisture module, capable of simulating workability and trafficability, might enable the Timelines model to predict occasions when ploughing and applications of solid manure in preparation for spring crops are made in the previous autumn. The Timelines model is therefore very much a work in progress. Finally, the data concerning the thermal time thresholds for sowing and harvesting that underlie the model are old and consider too few crops. The usefulness of complex ecosystem models in general and the Timelines model in particular would benefit if these data could be updated and expanded.

\section{Supplementary material related to this article is available online at: http://www.biogeosciences.net/9/ 4487/2012/bg-9-4487-2012-supplement.pdf.}

Acknowledgements. The authors would like to thank The European Commission and Aarhus University for financially supporting the NitroEurope research project (www.NitroEurope.eu), within which the presented research was undertaken.

Edited by: S. Reis

\section{References}

Amann, M., Asman, W., Bertok, I., Cofala, J., Heyes, C., Klimont, Z., Schöpp, W., and Wagner, F.: Cost-effective emission reductions to meet the environmental targets of the Thematic Strategy on Air Pollution under different greenhouse gas constraints, NEC Scenario Analysis Report Nr. 5, IIASA, Laxenburg, Austria, 67 pp., 2007.

Britz, W. and Witzke, H.-P.: CAPRI model documentation: Version 2, available at: http://www.capri-model.org, 2008.

CCM 250 DEM: EuroLandscape/Agri-Environment Catchment Characterisation and Modelling Activity, Land Management Unit, Institute for Environment and Sustainability, EC-Joint Research Centre, 250 Meter DEM, compiled on the basis of data acquired from data providers and national mapping agencies over Europe, http://afoludata.jrc.ec.europa.eu, 2004.

CEC: Report from the Commission to the Council and the European Parliament on implementation of Council Directive 91/676/EEC concerning the protection of waters against pollution caused by nitrates from agricultural sources for the period 2000-2003 SEC(2007)339 http://eur-lex.europa.eu/LexUriServ/LexUriServ. do?uri=COM:2007:0120:FIN:EN:PDF, 2007.

Chambers, B. J., Nicholson, N., Smith, K., Pain, B., Cumby, T., and Scotford, I. M.: Making better use of livestock manure on arable land, Anonymous, Anonymous, Gleadthorpe Research Centre, Mansfield, UK, ADAS, 2001.

Commission of the European Communities: Implementation of Council Directive 91/676/EEC concerning the protection of waters against pollution caused by nitrates from agricultural sources, Brussels, 17 July 2002, COM 407, http://eur-lex.europa.eu/LexUriServ/LexUriServ.do?uri=COM: 2002:0407:FIN:EN:PDF, 2002.

Cameron, D. R., Van Oijen, M., Werner, C., Butterbach-Bahl, K., Haas, E., Heuvelink, G. B. M., Grote, R., Kiese, R., Kuhnert, M., Kros, J., Leip, A., Reinds, G. J., Reuter, H. I., Schelhaas, M. J., De Vries, W., and Yeluripati, J.: Environmental change impacts on the C- and N-cycle of European forests: a model comparison study, Biogeosciences Discuss., 9, 11041-11101, doi:10.5194/bgd-9-11041-2012, 2012.

De Bruijn, A. M. G., Butterbach-Bahl, K., Blagodatsky, S., and Grote, R.: Model evaluation of different mechanisms driving freeze-thaw $\mathrm{N}_{2} \mathrm{O}$ emissions, Agr. Ecosys. Environ., 133, 196207, 2009.

De Vries, W., Leip, A., Reinds, G. J., Kros, J., Lesschen, J. P., and Bouwman, A. F.: Comparison of land nitrogen budgets for European agriculture by various modeling approaches, Environ. Pollut., 159, 3253-3267, 2011.

De Vries, W., Kros, J., Reinds, G. J., Wieggers, H. J. J., Velthof, G. L., Oudendag, D. A., Lesschen, J. P., Schelhaas, M. J., Perez Soba, M., Rienks, W., de Winter, W. P., Uijterwijk, M., van den Akker, J., Leip, A., Bakker, M. M., Verburg, P. H., Neumann, K., Liski, J., Eickhout B., and Bouwman, A. F.: Assessment of nitrogen and greenhouse gas fluxes at the European scale in response to land cover, livestock and land management change, Agr. Ecosys. Environ., in preparation, 2012.

Del Grosso, S. J. , Parton, W. J., Mosier, A. R., Walsh, M. K., Ojima, D. S., and Thornton, P. E.: DAYCENT national-scale simulations of nitrous oxide emissions from cropped soils in the United States, J. Environ. Qual., 35, 1451-1460, 2006. 
EEC: Protection of water against pollution by nitrates from agriculture, Anonymous, Anonymous, EEC/91/976, L375, 1991.

Jacob, D. A.: note to the simulation of the Annual and Interannual Variability of the Water Budget over the Baltic Sea Drainage Basin, Meteorol. Atmos. Phys., 77, 61-74, 2001.

Klok, E. J. and Klein Tank, A. M. G.: Updated and extended European dataset of daily climate observations, Int. J. Climatol., 29, 1182, doi:10.1002/joc.1779, 2009.

Leip, A., Marchi, G., Koeble, R., Kempen, M., Britz, W., and $\mathrm{Li}, \mathrm{C}$.: Linking an economic model for European agriculture with a mechanistic model to estimate nitrogen and carbon losses from arable soils in Europe, Biogeosciences, 5, 73-94, doi:10.5194/bg-5-73-2008, 2008.

Mitchell, T. D., Carter, T. R., Jones, P. D., Hulme, M., and New, M. A.: Comprehensive Set of High-resolution Grids of Monthly Climate for Europe and the Globe: The Observed Record (19012000) and 16 Scenarios (2001-2100), Tyndall Centre for Climate Change Research, 55, 30 pp., 2004.

New, M., Lister, D., Hulme, M., and Makin, I.: A high-resolution data set of surface climate over global land areas, Climate Res., 21, 1-25, 2002.

Orlandi, S. and Van der Goot, E.: Technical description of interpolation and processing of meteorological data in CGMS, Available under http://mars.jrc.ec.europa.eu/mars/content/download/ 640/4574/file/GridWeather.doc European Commission, DG JRC, Agrifish Unit, 2003.

Simpson, D., Butterbach-Bahl, K., Fagerli, H., Kesik, M., Skiba, U., and Tang, S.: Deposition and Emissions of Reactive Nitrogen over European Forests: A Modelling Study, Atmos. Environ., 40, 5712-5726, 2006.
Simpson, D., Benedictow, A., Berge, H., Bergström, R., Emberson, L. D., Fagerli, H., Flechard, C. R., Hayman, G. D., Gauss, M., Jonson, J. E., Jenkin, M. E., Nyíri, A., Richter, C., Semeena, V. S., Tsyro, S., Tuovinen, J.-P., Valdebenito, Á., and Wind, P.: The EMEP MSC-W chemical transport model - technical description, Atmos. Chem. Phys., 12, 7825-7865, doi:10.5194/acp-127825-2012, 2012.

Statistical Office of the European Communities (EUROSTAT): The Geographic Information System of the European Commission (GISCO) reference database, 7, Brussels, http://epp.eurostat. ec.europa.eu/portal/page/portal/nuts_nomenclature/history_nuts, 2003.

Van Diepen, K. and Boogaard, H.: History of CGMS in the MARS project, Agro Informatica, 22, 11-14, ISSN 0925-4455. 2009.

Van Groenigen, J. W., Velthof, G. L., van der Bolt, F. J. E. , Vos, A., and Kuikman, P. J.: Seasonal variation in $\mathrm{N}_{2} \mathrm{O}$ emissions from urine patches: Effects of urine concentration, soil compaction and dung, Plant Soil, 273, 15-27, 2005.

Wattenbach, M., Hillier, J., Schartner, T., Hattermann, F., Wechsung, F., van Oijen, M., de Vries, W., Reinds, G. J., Kros, J., Yeluripati, J., Kuhnert, M., Hutchings, N. J., Kiese, R., Werner, C., Butterbach Bahl, K., Leip, A., and Smith, P.: A generic probability-based algorithm to simulate the distribution of dominant crop types in time and space, Biogeoscience, in preparation, 2012.

Webb, J., Sorensen, P., Velthof, G. L., Amon, B., Pinto, M., Rohde, L., Salomon, E., Hutchings, N. J., Burczyk, P., Menzi, H., and Reid, J.: An assessment of the variation of manure nitrogen efficiency throughout Europe and an appraisal of means to increase manure $\mathrm{N}$ efficiency, advances in: Agronomy, 119, in press, 2012. 